\title{
Effects of pho Regulatory Mutations and pho A Gene Amplification on Alkaline Phosphatase Synthesis and Release by $l k y$ Mutants of Escherichia coli K12
}

\author{
By DANIELLE ATLAN,* JEAN-CLAUDE LAZZARONI AND \\ RAYMOND PORTALIER \\ Atelier de Biotechnologie Enzymatique et Microbienne (UM 380024), \\ Université Claude Bernard - Bât. 405 R3 - 69622 Villeurbanne Cedex, France
}

(Received 5 December 1984 ; revised 14 June 1985)

\begin{abstract}
lky mutants of Escherichia coli K12 spontaneously released alkaline phosphatase (APase) into the extracellular medium to give up to 300 units $\mathrm{ml}^{-1}$. APase is a phosphate repressible periplasmic enzyme encoded by the gene phoA. With a view to establishing a method of easy purification, we have analysed APase synthesis and release patterns of isogenic lky strains containing either a constitutive pho regulatory mutation, or a hybrid plasmid carrying the structural gene pho $A^{+}$and pho regulatory genes, or a transducing $\phi 80 p h o A^{+}$phage. In the presence of the phoS2333 mutation, $\mathrm{F}^{-} l k y$ strains lysogenized with $\phi 80$ phoBin $p h o A^{+}$phage and grown in high phosphate medium were able to release eight times more APase activity (2300 units $\mathrm{ml}^{-1}$ ) than haploid strain 2336 ( $p h o S^{+} l k y$ ) grown in low phosphate medium. Neither protein synthesis, the cell export machinery nor leakage mechanisms were limiting for APase release. Sufficient APase was released into the medium to facilitate its purification.
\end{abstract}

\section{INTRODUCTION}

In Escherichia coli, the enzyme alkaline phosphatase (EC 3.1.3.1; APase), which hydrolyses organic phosphate esters and releases inorganic orthophosphate $\left(\mathrm{P}_{\mathrm{i}}\right)$, is localized in the periplasmic space, an extracytoplasmic cell compartment bounded by the inner (cytoplasmic) and outer membranes of the bacterial cell envelope (Lugtenberg, 1981). APase synthesis is induced by growth with limiting concentrations of $P_{i}$ (Torriani, 1967). The expression of its structural gene, pho $A$, as well as that of other genes belonging to the phosphate ( $p h o$ ) regulon and coding for periplasmic (P2: sn-glycerol 3-phosphate binding protein; P4: phosphate binding protein) or outer membrane ( $\mathrm{PhoE}$ ) proteins is subject to a highly complex genetic control (Argast $\&$ Boos, 1980). It has been proposed that $p h o A$ gene expression is directly and positively regulated by the phoB gene product, and that $p h o B$ gene expression, in turn, is positively regulated by the phoM and phoR gene products, and negatively by the phoR, phoS, phoT (pstA), pst $B$ and pho $U$ gene products, directly or indirectly; it has also been shown that phoB, as well as phoA, is derepressed by phosphate limitation (for reviews see Tommassen \& Lugtenberg, 1982; Shinagawa et al., 1983; Ludtke et al., 1984; Nakata et al., 1984).

Translation of cell envelope proteins is initiated in the cytoplasm on membrane-bound ribosomes and transfer of these exported proteins across the inner membrane involves cotranslational and/or post-translational mechanisms (for reviews see Silhavy et al., 1983; Brickman et al., 1984). APase translocation into the periplasmic space is-carried out by a cotranslational process (Inouye et al., 1982).

Many Gram-positive bacteria produce exoenzymes but Gram-negative bacteria, like E. coli, generally do not release proteins into the culture medium (Glenn, 1976). We have described the

Abbreviations: APase, alkaline phosphatase; XP, 5-bromo-4-chloro-3-indolyl phosphate. 
isolation and characterization of $l k y$ and $e x c$ mutants which are spontaneously able to release periplasmic proteins like APase and $\beta$-lactamase into the culture medium (Lazzaroni \& Portalier, 1979, 1981; Fognini-Lefebvre \& Portalier, 1984), and we have determined the influence of culture conditions on APase synthesis and excretion by $l k y$ mutants (Atlan \& Portalier, 1984). In this study, we analyse the effects of pho regulatory mutations and pho $A$ gene amplification on the properties of $l k y$ strains.

\section{METHODS}

Strains. All strains used in this study were derived from Escherichia coli K 12 (Table 1). phoS65, phoS27, phoU (formerly called phoT35), pho 269 mutations and zib501::Tn 10 insertion were generously given by B. Bachmann ( $E$ coli Genetic Stock Center, New Haven, Connecticut 06515, USA). Tn 10 and Tn5 insertions in proC and gal genes respectively, were obtained from M. Gottesman's laboratory (NIH, Bethesda, Maryland 20205, USA). $\phi 80$ pho $A^{+}$and $\phi 80$ phoBin pho $A^{+}$hybrid bacteriophages were a gift of J. Beckwith (Harvard Medical School, Boston, Massachusetts 02115, USA).

\section{Table 1. Bacterial strains and plasmids}

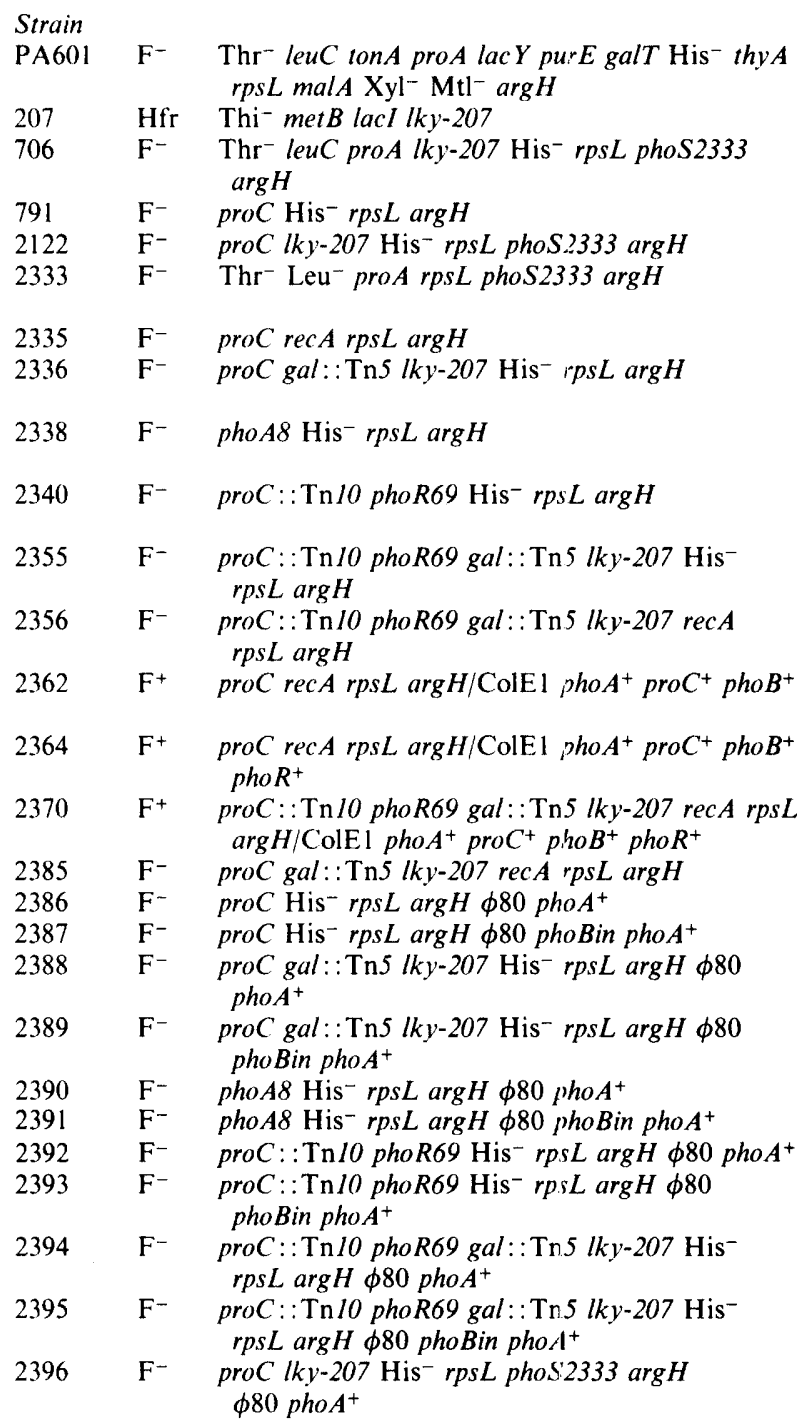

\section{Schwartz}

Lazzaroni \& Portalier (1979)

Periplasmic-leaky mutant of strain 2333 (Atlan \& Portalier, 1984)

Derivative of strain PA601; this work Derivative of strain 706; this work APase constitutive mutant of strain PA601 (Atlan \& Portalier, 1984)

recA derivative of strain 791 ; this work

Periplasmic-leaky mutant of strain 791 ; this work

APase deficient mutant of strain 791 ; this work

APase constitutive mutant of strain 791; this work

Periplasmic-leaky mutant of strain 2340 ; this work

$\operatorname{rec} A$ derivative of strain 2355 ; this work

Transformed strain 2335 with hybrid plasmid pJC719; this work

Transformed strain 2335 with hybrid plasmid pJC721; this work

Transformed strain 2356 with hybrid plasmid pJC721; this work rec $A$ derivative of strain 2336 ; this work Lysogen of strain 791 ; this work Lysogen of strain 791; this work Lysogen of strain 2336; this work

Lysogen of strain 2336; this work

Lysogen of strain 2338; this work Lysogen of strain 2338; this work Lysogen of strain 2340 ; this work Lysogen of strain 2340; this work

Lysogen of strain 2355 ; this work Lysogen of strain 2355 ; this work Lysogen of strain 2122; this work 
Table 1: (continued)

Sex

Relevant genotype or phenotype

Source

\begin{tabular}{|c|c|c|}
\hline Strain & & \\
\hline 2397 & $\mathrm{~F}^{-}$ & $\begin{array}{l}\text { proC lky-207 His- rpsL phoS2333 argH } \phi 80 \\
\text { phoBin pho } A^{+}\end{array}$ \\
\hline 2399 & $\mathrm{~F}^{+}$ & $\begin{array}{l}\text { proC gal : :Tn5 lky-207 recA rpsL argH/ColEl } \\
\text { phoA } A^{+} \text {pro } C^{+}\end{array}$ \\
\hline 2401 & $\mathrm{~F}^{+}$ & $\begin{array}{l}\text { proC gal::Tn5 } l k y-207 \text { rec A rpsL arg H/ColEl } \\
\text { pho } A^{+} \text {pro } C^{+} \text {pho } B^{+} \text {pho } R^{+}\end{array}$ \\
\hline 2407 & $\mathrm{~F}^{-}$ & proC $\mathrm{His}^{-}$rpsL zib501::Tn 10 phoS65 argH \\
\hline 2408 & $\mathrm{~F}^{-}$ & proC $\mathrm{His}^{-}$rpsL zib501::Tn10 phoS27 argH \\
\hline 2409 & $\mathrm{~F}^{-}$ & proC $\mathrm{His}^{-} r p s L$ zib501: $\mathrm{Tn} 10$ phoU argH \\
\hline 2410 & $\mathrm{~F}^{-}$ & $\begin{array}{l}\text { proC gal::Tn5 lky-207 His- rpsL zib501::Tn10 } \\
\text { phoS65 arg H }\end{array}$ \\
\hline 2411 & $\mathrm{~F}^{-}$ & $\begin{array}{l}\text { proC gal::Tns } 1 k y-207 \text { His rpsL zib501::Tn } 10 \\
\text { phoS27 argH }\end{array}$ \\
\hline 2421 & $F^{-}$ & $\begin{array}{l}\text { proC gal:: Tn5 lky-207 His- rpsL zib501::Tn10 } \\
\text { phoU argH }\end{array}$ \\
\hline 2438 & $\mathrm{~F}^{-}$ & $\begin{array}{l}\text { proC }:: \operatorname{Tn} 10 \text { lky-207 phoR69 } \text { His }^{-} \text {rpsL phoS2333 } \\
\text { argH } \phi 80 \text { phoBin pho } A^{+}\end{array}$ \\
\hline 2442 & $\mathrm{~F}^{-}$ & proC lky-207 $\mathrm{His}^{-}$rpsL phoS2333 argH $\phi 80$ \\
\hline $\begin{array}{l}\text { Plasmid } \\
\text { pJC719 }\end{array}$ & - & $\mathrm{ColEl}$ phoA $A^{+}$proC $C^{+}$phoB $B^{+}$ \\
\hline JC721 & - & ColEl phoA $A^{+}$proc $C^{+}$pho $B^{+}$pho $R^{+}$ \\
\hline
\end{tabular}

Lysogen of strain 2122 ; this work

Strain 2385 transformed with hybrid plasmid pJC719; this work

Strain 2385 transformed with hybrid plasmid pJC721; this work

APase constitutive mutant of strain 791: this work

APase constitutive mutant of strain 791; this work

APase constitutive mutant of strain 791; this work

Periplasmic-leaky mutant of strain 2407; this work

Periplasmic-leaky mutant of strain 2408 ; this work

Periplasmic-leaky mutant of strain 2409; this work

Derivative of strain 2397 ; this work

Lysogen of strain 2122; this work

Hybrid ColE1 plasmid (Lazzaroni \& Portalier, 1982)

Hybrid ColE1 plasmid (Lazzaroni \& Portalier, 1982)

Media, growth conditions and biomass. Modified rich Luria Broth (LB 8.3) was used as high phosphate medium, and minimal TRIS medium, supplemented with (per litre): glucose $(4 \mathrm{~g})$, proteose-peptone $(2 \mathrm{~g})$, thiamin hydrochloride $(1 \mathrm{mg})$ and appropriate amino acids $(40 \mathrm{mg}$ ), was used as low phosphate medium (Atlan \& Portalier, 1984). Isopropyl- $\beta$-D-thiogalactopyranoside (IPTG, Sigma) was added to the culture medium at a final concentration of $1 \mathrm{~mm}$ to induce $\beta$-galactosidase synthesis. Solid media contained $1.5 \%(\mathrm{w} / \mathrm{v})$ agar, and, if required, tetracycline hydrochloride $\left(10 \mathrm{mg} \mathrm{l}^{-1}\right.$, Sigma), kanamycin sulphate $\left(20 \mathrm{mg} \mathrm{l}^{-1}\right.$, Sigma), or 5-bromo-4chloro-3-indolyl phosphate (XP; $40 \mathrm{mg} \mathrm{l}^{-1}$, Sigma).

Routinely, $5 \mathrm{ml}$ cultures were inoculated from $8 \mathrm{~h}$ subcultures in the same medium, and allowed to grow for $16 \mathrm{~h}$ at $37^{\circ} \mathrm{C}$.

Biomass was estimated by measuring the $\mathrm{OD}_{600}$ of cell suspensions with a Jean \& Constant spectrophotometer (Prolabo, France): $100 \mathrm{OD}_{600}$ units correspond to $3 \times 10^{8}$ cells $\mathrm{ml}^{-1}$ or $0 \cdot 20 \mathrm{mg}$ of bacterial dry weight $\mathrm{ml}^{-1}$.

Enzyme extracts and assays. Cellular and extracellular extracts were obtained as described previously (Atlan \& Portalier, 1984). APase and $\beta$-galactosidase activities were assayed according to the procedures of Torriani (1967) and Miller (1972) respectively. One unit (U) of APase or $\beta$-galactosidase activity was defined as the amount of enzyme that hydrolyses $1 \mathrm{nmol}$ substrate $\mathrm{min}^{-1}$. An enzyme activity of $100 \%$ corresponds to the total intracellular plus extracellular activities. Total specific production corresponds to the increase of total (intracellular and extracellular) enzyme activity (mg bacterial dry weight increase) $)^{-1}$.

Electrophoretic analysis. Before electrophoresis, protein extracts were concentrated by ethanol precipitation at $-20^{\circ} \mathrm{C}$ for $4 \mathrm{~h}$ ( 1 vol. extract : 2 vols ethanol). After centrifugation $\left(40000 \mathrm{~g}, 30 \mathrm{~min},-20^{\circ} \mathrm{C}\right)$, protein pellets were resuspended in electrophoresis cracking buffer (Laemmli, 1970). Samples were boiled for 3 min under reducing conditions in the presence of $0.1 \mathrm{M}-\beta$-mercaptoethanol.

Sodium dodecylsulphate-polyacrylamide slab gel electrophoresis (SDS-PAGE) was done by the method of Laemmli (1970), except that TEMED $\left(N, N, N^{\prime}, N^{\prime}\right.$-tetramethylethylene diamine) and ammonium persulphate concentrations were respectively $0.033 \%$ and $0.035 \%$. Polyacrylamide gradients $(7-15 \%)$ were used routinely. Samples were electrophoresed for $16 \mathrm{~h}$ at $100 \mathrm{~V}$; gels were stained with $2 \%$ Coomassie blue as described by Lazzaroni \& Portalier (1981) and scanned with a Phi5 densitometer (Vernon, Paris, France).

Genetic techniques. $\operatorname{Tn} 10$ or $\operatorname{Tn} 5$ transposons or phoA 8 mutation were transferred by transduction with phage Plkc (Miller, 1972). Clones carrying transposons Tn 10 or Tn 5 were selected by their tetracycline or kanamycin resistance, respectively. pho $A$ mutated clones were identified in situ by a qualitative test (Lazzaroni \& Portalier, 1979) among Pro ${ }^{+}$transductants selected on proline deficient TRIS medium ( $p h o A$ and proC genes are $99 \%$ cotransducible). 
$\phi 80$ lysogens and lysates were obtained as described by Miller $(1972) ; \phi 80 p h o A^{+}$prophage excision was induced by UV light; lysates were used to infect an APase deficient strain (2338) on low phosphate solid medium containing XP (Inouye et al., 1981): $\phi 80$ pho $A^{+}$lysogenized clones appeared blue-coloured.

Hybrid ColEl plasmids were transferred into $\mathrm{F}^{-}$proC recA recipient strains $\left(l k y^{+}\right.$or $\left.l k y\right)$ by $\mathrm{F}$-mediated conjugation (Miller, 1972). Pro $^{+}$ColEl resistant conjugants were selected, and the presence of the plasmid was confirmed, by a second transfer into an appropriate recipient strain.

\section{RESULTS AND DISCUSSION}

\section{Influence of pho regulatory mutations on APase synthesis and release}

During growth in low phosphate medium, $p h o^{+}$periplasmic-leaky strain 2336 , carrying mutation $l k y-207$, had the same derepression pattern as parental strain $791\left(p h o^{+} l k y^{+}\right)$and produced equivalent amounts of APase, although it released up to $50 \%$ of its production into the medium (cellular lysis was estimated by measuring $\beta$-galactosidase activity in the medium) (Table 2). We have constructed isogenic derivatives of parental strains 791 and 2336 that carry a phoU, phoS, phoR or phoBin mutant allele and synthesize APase constitutively, even in the presence of a high phosphate concentration (about $10^{-3} \mathrm{M}$ ). The phoBin mutation is a promoterup mutation in the phoA gene promoter which makes the phoA gene expression independent of the positive effect mediated by the $p h o B$ gene product (Wanner et al., 1979). Strain 2333 was selected as an arsenate-resistant derivative of parental strain PA601, and had an APase constitutive pattern (Atlan \& Portalier, 1984); as plasmid pSN518 carrying gene pho ${ }^{+}$ (Amemura et al., 1982) suppressed this mutation, we named it phoS2333 (J. C. Lazzaroni \& R. Portalier, unpublished results).

After growth in low phosphate medium (Table 2), phoR strains $2340\left(l k y^{+}\right)$and $2355(l k y)$ did not synthesize more APase than parental strains 791 and 2336, respectively. However, other constitutive strains carrying a $l k y^{+}$or $l k y$ allele showed a marked increase in APase activities. phoS2333 clones, which synthesized three times more enzyme than parental strains, were characterized by the highest specific production of APase. phoS65 leaky strain 2410 had the highest proportion of APase leakage (60\% of total APase production).

After growth in high phosphate medium (Table 2), all lky strains carrying a constitutive pho mutation synthesized and released APase. However, the lowest APase production, measured with phoBin strain $2389\left(111 \mathrm{U} \mathrm{ml}^{-1}\right)$, was 14 times less than the highest, measured in phoS2333 strain $2122\left(1483 \mathrm{U} \mathrm{ml}^{-1}\right)$. The specific production of APase of constitutive derivatives grown in high phosphate medium was always lower than that observed in low phosphate medium; moreover, in the former medium, lky mutants released a greater proportion of APase and cell lysis, reflected by the extracellular level of $\beta$-galactosidase activity, was lower. We have checked that the presence of $\operatorname{Tn} 10$ or $\operatorname{Tn} 5$ transposons in $l k y$ strains did not alter APase leakage level and cellular stability (data not shown).

These results showed that $l k y$ mutants, except strain 2122, produced as much APase as their non-excretory isogenic parents; the marked increase in the specific activity of APase observed with strain 2122 grown in low phosphate medium could indicate a new regulatory mechanism for APase synthesis induced in the phoS2333 mutant by enzyme excretion in order to maintain a constant periplasmic enzyme content. Moreover, total APase derepression was not achieved in a pho ${ }^{+}$wild-type strain; even in low phosphate medium, some $p h o^{+}$regulatory gene products still exerted a repressive effect on APase synthesis or export.

\section{Protein content of extracellular fluids from APase constitutive lky mutants}

The protein composition of culture supernatants after growth in high phosphate medium was analysed by SDS-PAGE (Fig. 1). As we have shown previously (Atlan \& Portalier, 1984), four major periplasmic proteins were released into the medium by APase constitutive lky mutants. One protein had a molecular weight of $58 \mathrm{kDal}$, and three were phosphate-regulated polypeptides: APase monomer (P1: $45 \mathrm{kDal})$; sn-glycerol-3-phosphate binding protein (P2; $41.5 \mathrm{kDal})$ and phosphate binding protein (P4; $31.5 \mathrm{kDal})$. These four periplasmic proteins, as well as other minor unidentified polypeptides, were released by $l k y$ mutants 2411 ( $p h o S 27$ ), 2355 


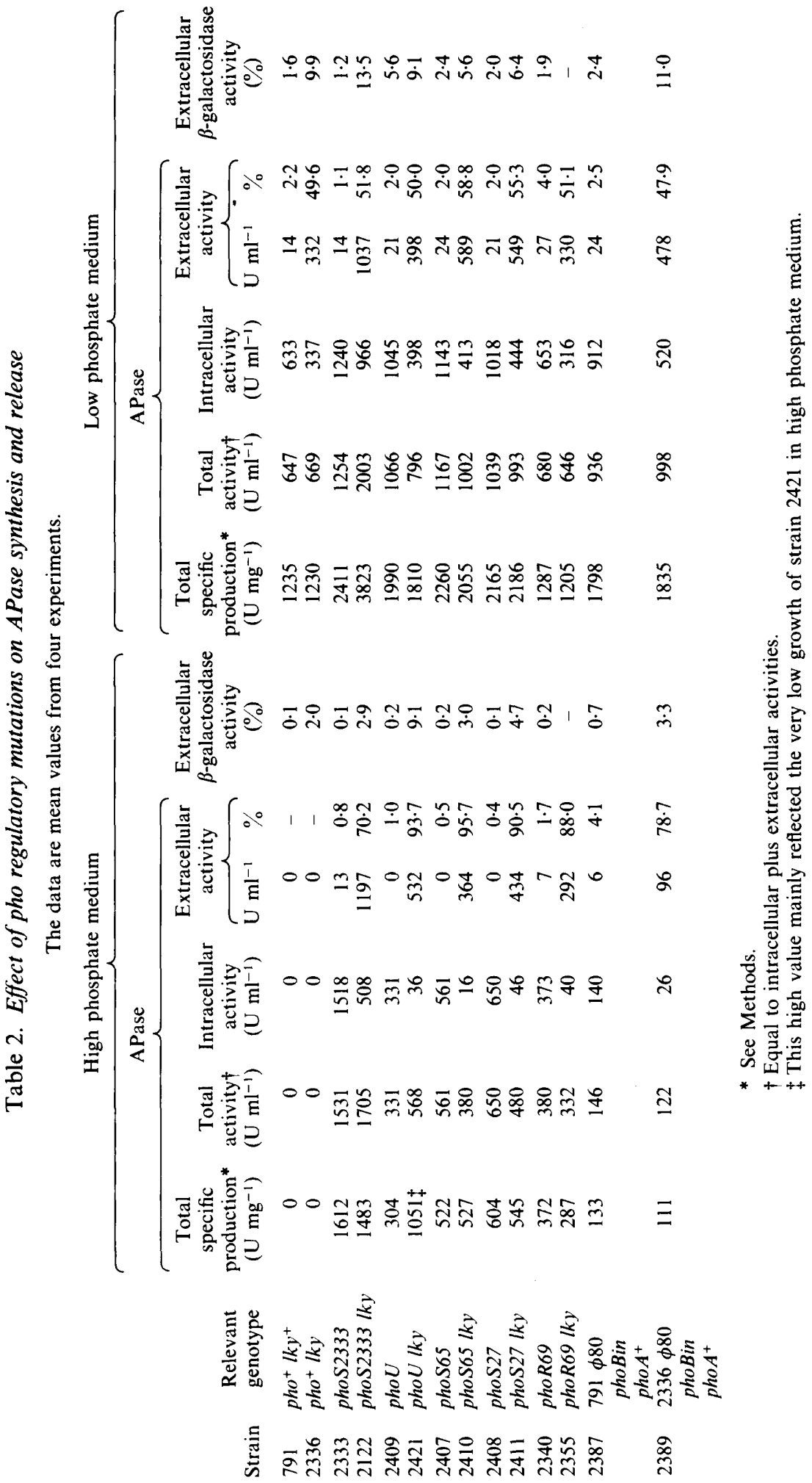




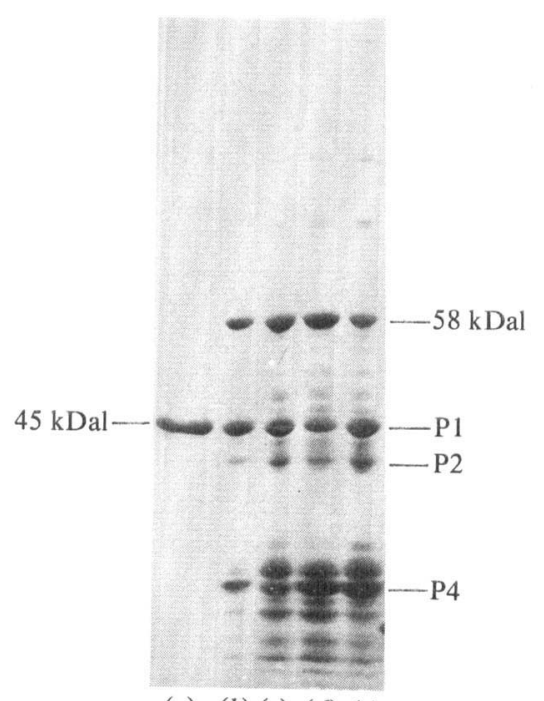

(a) $(b)(c)(d)(e)$

Fig. 1. SDS-polyacrylamide gradient (7-15\%) gel electrophoretic analysis of commercial A Pase (Sigma P9761) (a) and extracellular proteins released by APase constitutive $l k y$ strains : $2122(b), 2411$ (c), 2355 $(d)$ and $2421(e)$. Samples containing $350 \mathrm{U}$ APase activity were loaded in each well. Bacteria were grown in high phosphate medium anc were collected in late stationary phase.

(phoR69), 2421 (phoU) and 2122 (phoS2333); P1 monomer accounted for 15\%,8\%, 15\% and $26 \%$ of the total amount of excreted proteins, respectively. Moreover, with the latter mutant, APase was the major released protein.

\section{Effect of phoA gene amplification on APase synthesis and release}

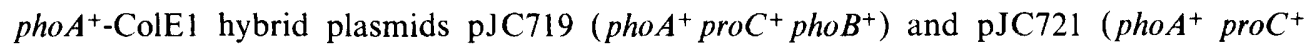
pho $B^{+}$pho $R^{+}$) (Lazzaroni \& Portalier, 1982) were introduced by F-mediated conjugation into recA $l k y^{+}(2335)$ or $l k y \mathrm{~F}^{-}$(2385) recipient strains. Total APase activities of plasmid-bearing $l k y^{+}$transconjugants 2362 and 2364 grown in derepression conditions were eight times higher than those of haploid strain 2335 , whereas pho $R^{+}$or phoR $l k y$ transconjugants only synthesized twice the amount of APase produced by haploid strains 2385 or 2356 (Table 3). We do not know if the presence of the mutation $l k y-2.07$ in the genetic background of strain PA601 limited the replication of ColEl-derived plasmids or the cell's capacity to synthesize or export APase.

In high phosphate medium, APase was constitutively synthesized by plasmid-bearing derivatives of repressible strain 2335, although strain 2364 containing plasmid pJC721 was the only one to produce high enzyme levels. We were unable to transfer pho $A^{+}$-ColEl plasmids into the phoS2333 rec $\mathrm{Alky}^{+}$or $l \mathrm{ky}$ strains: in order to get more information on the ability of periplasmic-leaky mutants to synthesize and release high amounts of APase in high phosphate medium, we used an independent genetic approach, as described below.

APase synthesis and release by $\phi 80$ pho $A^{+}$or $\phi 80$ phoBin pho $A^{+}$lysogenized cells

$l k y^{+}$and $l k y$ strains carrying wild-type or mutant pho regulatory alleles were lysogenized with hybrid bacteriophage $\phi 80 p h o A^{+}$or $\phi 80$ phoBin pho $A^{+}$. APase synthesis and release properties of lysogenized strains are shown in Table 4.

Expression of the pho $A^{+}$gene carried by the $\phi 80$ hybrid phages, and present as a single copy in strains 2390 and 2391, was phosphate-repressible, as it was for the pho $A^{+}$chromosomal gene in wild-type strain 791 . On the other hand, during growth in low phosphate medium, strains 2386 and 2388 , which carry two copies of the $p h o A^{+}$gene, synthesized twice as much APase as their haploid parents 791 and 2336. Gene dosage experiments with phoR or phoS constitutive strains 


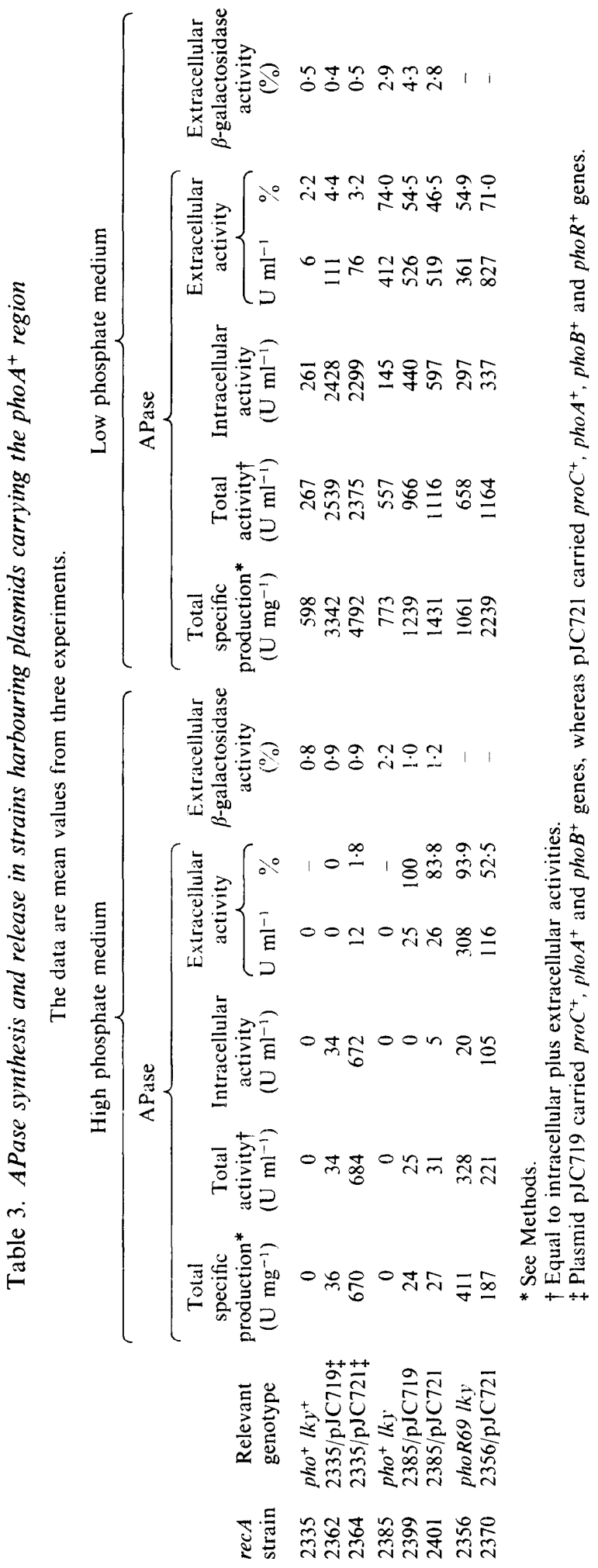




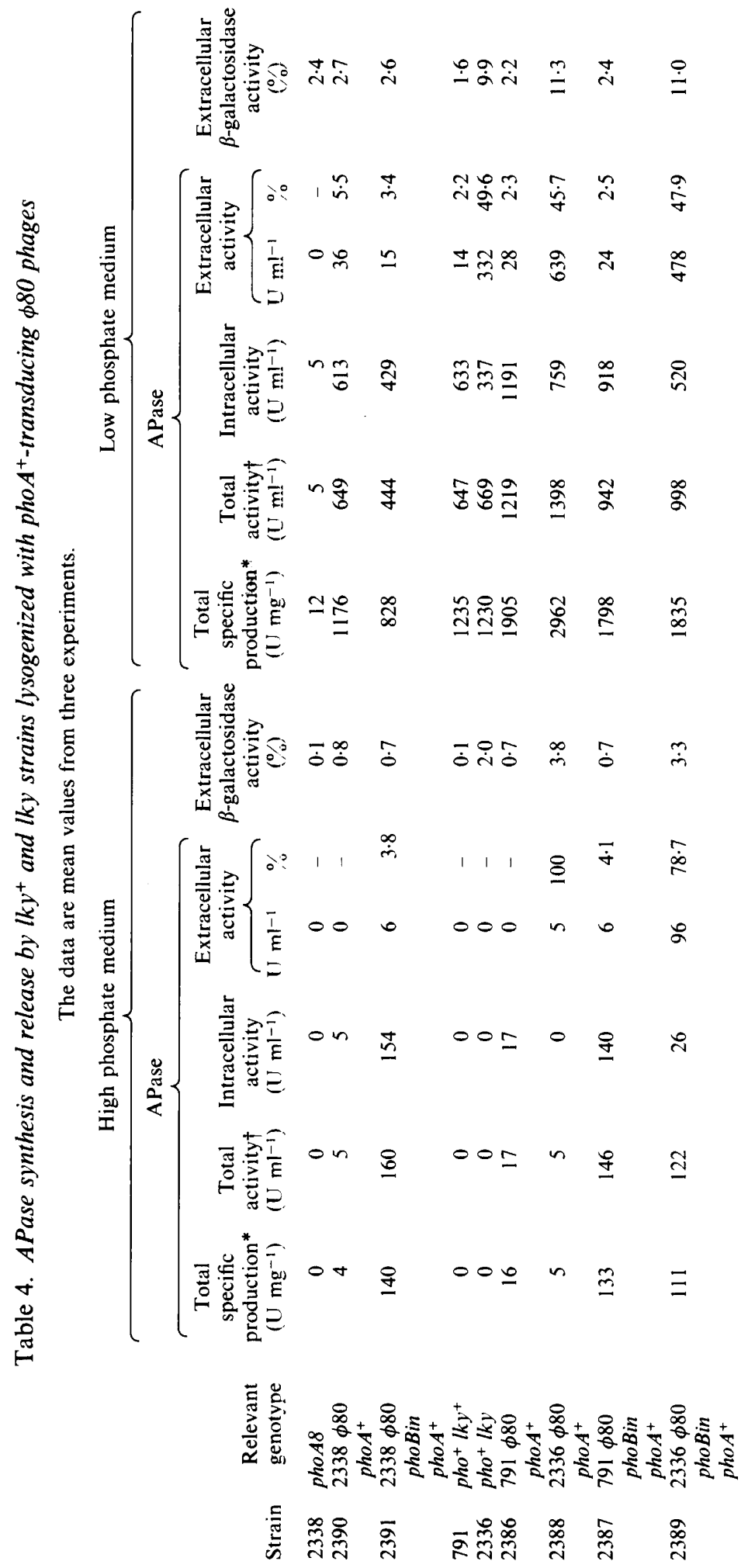




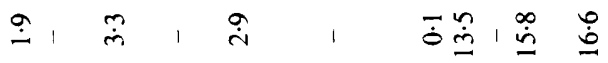

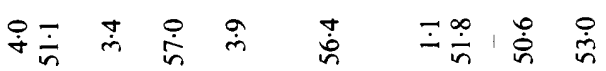

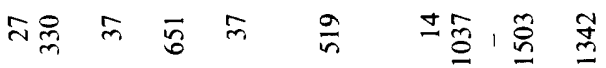

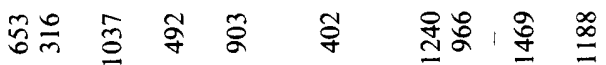

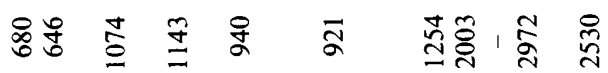

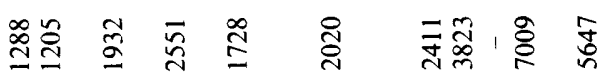

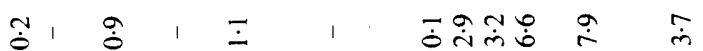

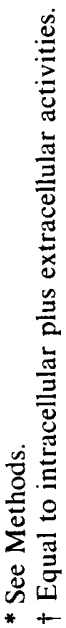

每

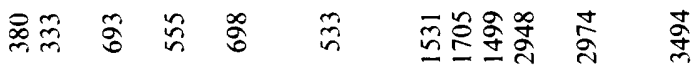

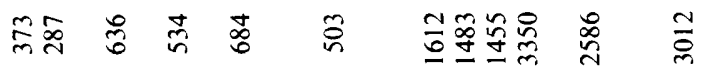

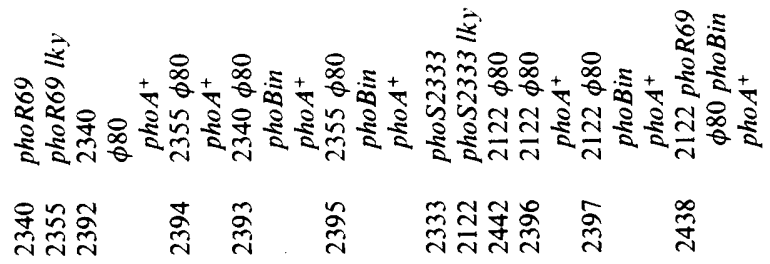


Table 5. Relative contribution of periplasmic proteins to the extracellular medium from $l k y$ phos mutants grown in high phosphate medium

Cells were grown in high phosphate medium. The data are mean values from two experiments.

\begin{tabular}{llcccc} 
& & \multicolumn{3}{c}{ Relative contribution of periplasmic proteins } \\
Strain & $\begin{array}{c}\text { Relevant } \\
\text { genotype }\end{array}$ & $58 \mathrm{kDal}$ & $\begin{array}{c}\text { P1 } \\
\text { (APase } \\
\text { monomer) }\end{array}$ & $\mathrm{P} 2$ & $\mathrm{P} 4$ \\
2122 & phoS2333lky & 20 & 26 & 7 & 18 \\
2442 & $2122 \phi 80$ & 20 & 25 & 4 & 23 \\
2396 & $2122 \phi 80$ phoA & 14.5 & 40 & 1.5 & 16.5 \\
2397 & $2122 \phi 80$ phoBin phoA & 16.5 & 43 & 1.5 & 18
\end{tabular}

grown in low or high phosphate medium similarly showed that partial diploid strains synthesized about twice as much APase as haploid strains. These results also demonstrated that lky mutants 2396 and 2397 were able to export and process high APase levels $\left(3000 \mathrm{U} \mathrm{ml}^{-1}\right)$, and to release up to $2300 \mathrm{U} \mathrm{ml}^{-1}$ after growth in rich, high phosphate medium, i.e. twice the amount of enzyme released by haploid strain 2122 .

Molecular mechanisms involved in the APase leakage process were not saturated when cells were grown in high phosphate medium, and APase did not accumulate in the periplasm of $l k y$ mutants; however, this was not the case for $l k y$ strains 2396 and 2397 during growth in low phosphate medium.

The phoBin mutated promoter enabled APase synthesis to occur in repressed conditions, but was less efficient than the wild-type promoter for initiating phoA gene transcription in derepressed conditions.

For further studies on extracellular fluids of $l k y$ mutants we used rich, high phosphate medium (Atlan \& Portalier, 1984) which allowed fast growth, low cellular lysis and high APase release. Protein content of extracellular fluids from lky phoS2333 mutants lysogenized with $\phi 80$ pho $A^{+}$or
$\phi 80$ phoBin pho $A^{+}$phages

Quantitative relationships between major periplasmic proteins released by $l k y p h o S 2333$ lysogens are shown in Table 5. The increase in total extracellular APase activities observed with lysogenized strains (Table 4) was correlated with an increase in the relative APase content in the extracellular medium. The enzyme accounted for up to $43 \%$ of total released proteins (strain 2397), a proportion which facilitates its purification.

\section{Conclusions}

Several conclusions can be drawn from our study of the properties of the leaky strains we have constructed. First, in low phosphate medium, all haploid constitutive $l k y$ strains released $50 \%$ of their total APase activity whatever the nature of the constitutive mutation was, and even when specific activities of APase were very high. These results suggest that the mechanisms involved in the APase leakage operate independently of the pho regulon.

Second, availability of APase constitutive strains allowed us to study the release process during growth in rich medium, in the presence of excess phosphate. Under these conditions, specific activities were lowered but the proportion of extracellular APase increased significantly from $50 \%$ to $70-95 \%$. These results suggest that a rich-medium-inducible mechanism directly or indirectly stabilizes the inner membrane (hence less $\beta$-galactosidase leakage) but destabilizes the outer membrane, so increasing leakage of periplasmic constituents. Studies are now underway to elucidate the nature of this regulation.

APase overproduction had already been obtained by several authors (Berg, 1981; Inouye et al., 1981; Lazzaroni \& Portalier, 1982) but their studies were done in conditions of phosphate starvation. We have now taken advantage of the high quantities of APase released by constitutive mutants in high phosphate medium to develop a new and simple method for APase purification (D. Atlan \& R. Portalier, unpublished results). 
This work was supported by grants from the Centre National de la Recherche Scientifique (LP 05421) and the Ministère de l'Education Nationale. We are indebted to B. Bachmann for sending pho regulatory strains, to

J. Beckwith for hybrid-pho $A^{+} \phi 80$ bacteriophages and to M. Gottesman for $\operatorname{Tn} 10$ and $\operatorname{Tn} 5$ transposons.

\section{REFERENCES}

Amemura, M., Shinagawa, H., Makino, K., Otsuji, N. \& NAKATA, A. (1982). Cloning and complementation tests with alkaline phosphatase regulatory gene (phos and phoT) of Escherichia coli. Journal of Bacteriology 152, 692-701.

ARGaSt, M. \& Boos, W. (1980). Co-regulation in Escherichia coli of a novel transport system for $s n^{-}$ glycerol-3-phosphate and outer membrane protein Ic (e,E) with alkaline phosphatase and phosphatebinding protein. Journal of Bacteriology 143, 142150.

Atlan, D. \& Portalier, R. (1984). Optimized extracellular production of alkaline phosphatase by lky mutants of Escherichia coli K 12. Applied Microbiology and Biotechnology 19, 5-12.

BERG, P. (1981). Cloning and characterization of the Escherichia coli gene coding for alkaline phosphatase. Journal of Bacteriology 146, 660-667.

Brickman, E., Oliver, D., Garwin, J., Kumamoto, C. \& Beckwith. J. (1984). The use of extragenic suppressors to define genes involved in protein export in Escherichia coli. Molecular and General Genetics 196, 24-27.

Fognini-Lefebvre, N. \& Portalier, R. (1984). Isolation and preliminary characterization of $\beta$ lactamase periplasmic-leaky mutants of $E$. coli $\mathrm{K}-12$. FEMS Microbiology Letters 21, 323 -328.

GlenN, A. R. (1976). Production of extracellular proteins by bacteria. Annual Review of Microbiology 30, 41-62.

INouYe, H., Michaelis, S., Wright, A. \& BeCKWITH, J. (1981). Cloning and restriction mapping of the alkaline phosphatase structural gene (phoA) of Escherichia coli and generation of deletion mutants in vitro. Journal of Bacteriology 146, 668-675.

INOUYE, H., BARNES, W. \& BECKWITH, J. (1982). Signal sequence of alkaline phosphatase of Escherichia coli. Journal of Bacteriology 149, 434-439.

LAEMMLI, U. (1970). Cleavage of structural proteins during the assembly of the head of bacteriophage T4. Nature, London 227, 680-685.

Lazzaroni, J. C. \& Portalier, R. (1979). Isolation and preliminary characterization of periplasmicleaky mutants of Escherichia coli K 12. FEMS Microbiology Letters 5, 411-416.
Lazzaroni, J. C. \& Portalier, R. (1981). Genetic and biochemical characterization of periplasmic-leaky mutants of Escherichia coli K12. Journal of Bacteriology 145, 1351-1358.

Lazzaroni, J. C. \& Portalier, R. (1982). Production of extracellular alkaline phosphatase by Escherichia coli $\mathrm{K} 12$ periplasmic-leaky mutants carrying pho $A^{+}$ plasmids. European Journal of Applied Microbiology and Biotechnology 16, 146-150.

LudTKe, D., Bernstein, J., Hamilton, C. \& TORRIANI, A. (1984). Identification of the pho $M$ gene product and its regulation in Escherichia coli K12. Journal of Bacteriology 159, 19-25.

LUGTENBERG, B. (1981). Composition and function of the outer membrane of Escherichia coli. Trends in Biochemical Sciences 6, 262-266.

MilleR, J. (1972). Experiments in Molecular Genetics. Cold Spring Harbor, New York: Cold Spring Harbor Laboratory.

NaKata, A., Amemura, M. \& Shinagawa, H. (1984). Regulation of the phosphate regulon in Escherichia coli K12: Regulation of the negative regulatory gene pho $U$ and identification of the gene product. Journal of Bacteriology 159, 979-985.

Shinagawa, H., Makino, K. \& Nakata, A. (1983). Regulation of the pho regulon in Escherichia coli $\mathrm{K} 12$. Genetic and physiological regulation of the positive regulatory gene ( $p h o B$ ) expression. Journal of Molecular Biology 168, 477-488.

Silhavy, T., Benson, S. \& EMR, S. (1983). Mechanisms of protein localization. Microbiological Reviews 47, 313-344.

Tommassen, J. \& Lugtenberg, B. (1982). pho regulon of Escherichia coli K12: a minireview. Annales de Microbiologie 133A, 243-249.

TORRIANI, A. M. (1967). Alkaline phosphatase from Escherichia coli. In Procedures in Nucleic Acid Research, pp. 224-235. Edited by G. L. Cantoni \& D. R. Davies, New York: Harper and Row.

W ANNER, B., SARTHY, A. \& BeCKWITH, J. (1979). Escherichia coli pleiotropic mutant that reduces amounts of several periplasmic and outer membrane proteins. Journal of Bacteriology 140, 229-239. 